\title{
Theoretical Study on Dynamics Quality of Aerostatic Thrust Bearing with External Combined Throttling
}

\author{
Vladimir A. Kodnyanko \\ Professor \\ Polytechnical Institute \\ Siberian Federal University \\ Russia \\ Stanislav N. Shatokhin \\ Professor \\ Polytechnical Institute \\ Siberian Federal University \\ Russia
}

The article considers the design, mathematical modelling and theoretical study of dynamics quality on aerostatic thrust bearing with external combined air double throttling and flow cavity. The use of the finitedifference method for solving boundary value problems for linearised and Laplace-transformed Reynolds equation allowed to obtain its solution with high accuracy. The quality indicators of bearing dynamics were studied depending on the damping and throttling resistances, as well as on the volume of the cavity. It is established that the presence of a cavity contributes to a significant improvement in the quality indicators of the bearing dynamics. Based on the analysis of the data obtained, conclusions are drawn confirming the hypothesis that with a targeted choice of the values of the external throttling system parameters, a design can be obtained that, in comparison with the known aerostatic bearings, will have much better dynamic characteristics.

Key words: aerostatic thrust bearing, resonator cavity, double throttling, damping resistance, throttling resistance, carrier gap compliance, quality of dynamics.

\section{INTRODUCTION}

Aerostatic bearings are widely used in various fields of mechanical engineering, providing high accuracy, low friction and low heat $[1-6]$.

Passive type aerostatic bearings with throttle control of air discharge have received the main practical application. Structures having input throttling resistances in the form of nozzles with simple diaphragms and shallow pockets at their outlet have the highest load characteristics $[7,8]$. To reduce the number and increase the diameter of the nozzles on the working surface of the bearing sleeve along the nozzle location line, micro grooves are applied $[9,10]$.

Aerostatic bearings with inlet throttling resistances in the form of nozzles with annular diaphragms have one and a half times less compliance and worse load characteristics [11].

Aerostatic bearings have an increased tendency to unstable operating modes (such as "pneumatic hammer") due to the high compressibility of the air. Traditional methods for increasing the stability of such bearings are usually reduced to the ultimate reduction in the volume of cavities (grooves, pockets) enclosed between external chokes and the carrier gas layer, which complicates the construction of the bearing and complicates its manufacture $[12,13]$.

The insufficiently studied method of increasing the stability of aerostatic bearings based on the use of closed resonant cavities connected by a throttling channel

Received: December 2019, Accepted: February 2020

Correspondence to: Dr Vladimir Kodnyanko

Polytechnical Institute, Siberian Federal University,

Kirensky Str. 28, 660074, Krasnoyarsk, Russia

E-mail: kowlad@rambler.ru

doi:10.5937/fme2002342K

(C) Faculty of Mechanical Engineering, Belgrade. All rights reserved to the supply pocket of the bearing is quite noteworthy [14-16]. Such bearings may well have better dynamic characteristics and, therefore, external chokes can be placed in them, which would provide the least flexibility without compromising the quality of the dynamics of the bearings.

The purpose of this theoretical study is to examine the dependence of the dynamic characteristics of the bearing on the ratio of the resistances of the damping and throttling nozzles, as well as to verify the assumption that, with the presence of an additional flow resonant cavity, the cavity should improve the dynamic characteristics of the bearing.

\section{DESIGN SCHEME AND MATHEMATICAL MODEL OF THE BEARING}

Fig. 1 shows the design diagram of the considered aerostatic bearing, which has a fixed thrust bearing 1 and a rotating heel 2 of radius $r_{b}$. The mating working surfaces of the heel and the thrust bearing are separated by a thin carrier gas gap 6, which is created by external injection of compressed air and non-contact balances the effect of the external load $f$. Heel 2 has a simple diaphragm 3, through which compressed air is pumped into the inter-throttle resonant cavity 5 . From the cavity compressed air enters the carrier gas gap of the bearing through a system of damping annular diaphragms 4, evenly spaced around the circle of radius $r_{c}$.

The fundamental difference between the considered bearing and conventional bearings is that cavity 5 is made flowing and is located in the discharge path between throttle 3 and damping annular diaphragms 4 .

The following notation is used in the work: $\mu$ is the coefficient of dynamic viscosity of air; $T$ is the absolute air temperature; $\mathfrak{R}$ is the gas constant; $\gamma=1.41$ is the 
adiabatic exponent [14]; $r_{b}, r_{c}$ are the radii of the bearing; $r$ is the current coordinate of the radius; $t$ is the current time; $c_{k}, c_{p}$ are the coefficients of outflow from the throttling and damping nozzles; $m$ is the mass of the heel $2 ; p(r, t)$ is the pressure function in the carrier gas gap; $q_{p}(t), q_{k}(t), q_{h}(t)$ are the mass air flow rates through the throttles 3, 4 and the carrier gap 5, respectively; $f$ is the external load.

A theoretical study of the bearing dynamics quality is performed using dimensionless quantities.

The following are taken for their scale: $r_{b}$ for radii; $p_{a}$ for pressures; $h_{0}$ for the current gap thickness; $t_{0}$ for the current time; $h_{0}^{3} p_{a}^{2} / \mu \Re T$ for mass flow rates; $r_{b}^{2} p_{a}$ for forces, where $h_{0}$ is the gap thickness in the so-called "design point" mode.

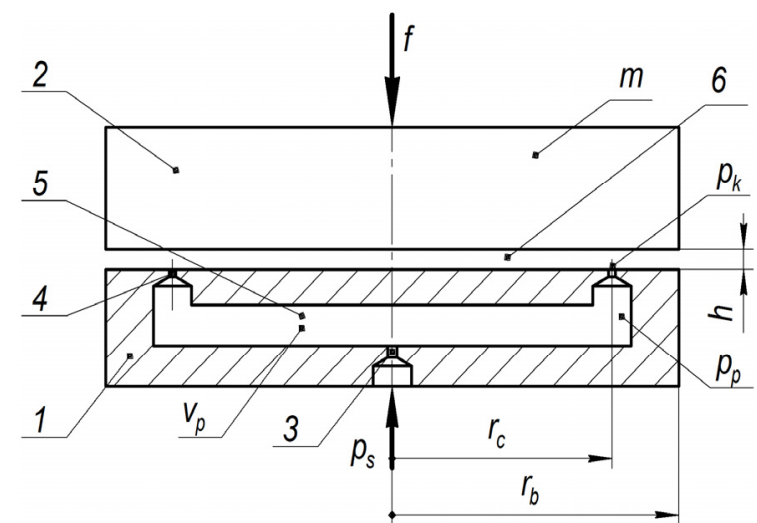

Figure 1. Aerostatic thrust bearing with external double combined throttling

The "design mode" corresponds to dimensionless static pressures $P_{k}=P_{k 0}, P_{p}=P_{p 0}$ and air film thickness $H=1$, which can be calculated through the throttling and damping coefficients of the lubricant supply system into the bearing gap

$$
\chi=\frac{P_{k 0}^{2}-1}{P_{s}^{2}-1} \in[0,1], \quad \varsigma=\frac{P_{p 0}^{2}-P_{k 0}^{2}}{P_{s}^{2}-P_{k 0}^{2}} \in[0,1] .
$$

At $\varsigma=0$, the developed mathematical model corresponds to an aerostatic bearing with a single external throttling with simple diaphragms, and at $\varsigma=1-$ an aerostatic bearing with a single external throttling with annular diaphragms. Intermediate values $\varsigma$ correspond to a bearing with a combined external double throttling and an inter-throttle resonant cavity.

Using (1), we determined the dimensionless static analogues of boundary pressures

$$
P_{k 0}=\sqrt{1+\chi\left(P_{s}^{2}-1\right)}, \quad P_{p 0}=\sqrt{P_{k 0}^{2}+\varsigma\left(P_{s}^{2}-P_{k 0}^{2}\right)} .
$$

The dynamics of the bearing under consideration is described by a system of dimensionless equations of continuity of air flow through cavity 5, carrier gap 6 , and the equilibrium equation of forces acting in a conservative system (d'Alembert principle) [17]

$$
\left\{\begin{array}{l}
Q_{p}-Q_{v}-Q_{k}=0, \\
Q_{k}-Q_{h}=0, \\
W-F_{i n}=F,
\end{array}\right.
$$

where the flow rate through resistance 3 [18].

$$
Q_{p}=A_{p} \Pi\left(P_{s}, P_{p}\right),
$$

flow rate through resistance 4 [18]

$$
Q_{k}=A_{k} H \Pi\left(P_{p}, P_{k}\right),
$$

flow rate taking into account the compressibility of the lubricant in the cavity 5 [7]

$$
Q_{v}=A_{v} \frac{d P_{p}}{d \tau}
$$

flow rate in the lubricant gap with thickness $H$ [7]

$$
Q_{h}=-H^{3}\left[\left(R \frac{\partial P^{2}}{\partial R}\right)_{R=R_{c}+0}-\left(R \frac{\partial P^{2}}{\partial R}\right)_{R=R_{c}-0}\right],
$$

bearing capacity [8]

$$
W=2 \pi \int_{0}^{1} R(P-1) d R
$$

mass inertia force of heel 1 [8]

$$
F_{i n}=M_{p} \frac{d^{2} H}{d \tau^{2}}
$$

Prandtl function for flow rate from diaphragms $[18,19]$

$$
\Pi\left(P_{1}, P_{2}\right)= \begin{cases}\sqrt{\left(P_{1}-P_{2}\right) P_{2}}, & P_{2} / P_{1}>0.5, \\ 0.5 P_{1}, & P_{2} / P_{1} \leq 0.5,\end{cases}
$$

as well as dimensionless parameters:

$\tau$ is the dimensionless time,

$M_{p}=\frac{m h_{0}}{t_{0}^{2} r_{b}^{2} p_{a}}$ is the mass of heel 1,

$V_{p}=\frac{v_{p}}{\pi r_{b}^{2} h_{0}}$ is the volume of cavity 5 ,

$\sigma=\frac{12 \mu r_{b}^{2}}{h_{0}^{2} p_{a} t_{0}}$ is the so-called "compression number" of the gas film [19],

$A_{v}=\frac{\pi \sigma V_{p}}{12}, A_{p}=\frac{\Gamma c_{p} d_{p}^{2}}{h_{0}^{3} p_{a}}, \quad A_{\kappa}=\frac{4 \Gamma n_{k} c_{k} d_{k}}{h_{0}^{2} p_{a}}$ are similarity coefficients for costs through the carrier gap, throttling and damping orifices,

$$
\Gamma=3 \gamma\left(\frac{2}{\gamma+1}\right)^{\frac{\gamma+1}{2(\gamma-1)}} \sqrt{\Re T} \text { is gas constant. }
$$

The pressure function $P(R, \tau)$ is a solution of the nonstationary Reynolds equation [5]

$$
H^{3} \frac{\partial}{\partial R}\left(R P \frac{\partial P}{\partial R}\right)=\sigma R \frac{\partial(P H)}{\partial \tau}
$$

with initial condition

$$
P(R, 0)=P_{0}(R)
$$

and boundary conditions

$$
\frac{\partial P(0, \tau)}{\partial R}=0, P\left(R_{c}, \tau\right)=P_{k}(\tau), P(1, \tau)=1 .
$$

Here

$$
P_{0}(R)= \begin{cases}P_{k 0}, & 0 \leq R \leq R_{c}, \\ \sqrt{\left(P_{k 0}^{2}-1\right) \frac{\ln R}{\ln R_{c}}+1,} & R_{c}<R \leq 1\end{cases}
$$


is the solution of a stationary problem

$$
\left\{\begin{array}{l}
\frac{d}{d R}\left(R P_{0} \frac{d P_{0}}{d R}\right)=0, \\
\frac{d P_{0}(0)}{d R}=0, P_{0}\left(R_{1}\right)=P_{k 0}, P_{0}(1)=1 .
\end{array}\right.
$$

Using (2), we write the system of equations of the stationary equilibrium of the bearing in the "design point" mode

$$
\left\{\begin{array}{l}
Q_{p 0}-Q_{k 0}=0 \\
Q_{k 0}-Q_{h 0}=0
\end{array}\right.
$$

As follows from (5), (12)

$$
Q_{h 0}=A_{h}\left(P_{k 0}^{2}-1\right),
$$

where $A_{h}=-1 / \ln R_{c}$.

At known pressures of the "design point" mode and supply pressure, similarity criteria for the throttles can be found

$$
A_{k}=\frac{Q_{h 0}}{\Pi\left(P_{k 0}, P_{p 0}\right)}, \quad A_{p}=\frac{Q_{h 0}}{\Pi\left(P_{p 0}, P_{s}\right)} .
$$

\section{METHOD FOR CALCULATING THE STATIC AND DYNAMIC CHARACTERISTICS OF THE BEARING}

When calculating the static characteristics of the bearing, $P_{s}, R_{c}, \chi, \varsigma$ were used as input parameters. Then, at $H=1$, the pressures of the "design point" mode $P_{k 0}, R_{p 0}$ were determined by formulas (2) and the similarity coefficients $A_{h}, A_{k}, A_{p}$ by formulas (16), (17).

To construct the load characteristic $H(F)$ by varying the pressure $P_{k} \in\left[1, P_{s}\right]$, we calculated the static bearing capacity

$$
W=\pi\left[R_{c}^{2}\left(P_{k}-1\right)+2 \int_{R_{c}}^{1} R\left(P_{0}-1\right) d R\right]
$$

and determined the current thickness $H$ of the bearing carrier gap by solving the system of nonlinear equations arising from (3) - (5), (7), (14)

$$
\left\{\begin{array}{l}
A_{h} H^{3}\left(P_{k}^{2}-1\right)-A_{k} H \Pi\left(P_{p}, P_{k}\right)=0, \\
A_{p} \Pi\left(P_{s}, P_{p}\right)-A_{k} H \Pi\left(P_{p}, P_{k}\right)=0 .
\end{array}\right.
$$

System (19) can be reduced to a nonlinear equation $A_{s} \Pi\left(P_{s}, P_{p}\right) \sqrt{P_{k}^{2}-1}-\Pi^{3 / 2}\left(P_{p}, P_{k}\right)=0$

in relation to the unknown pressure $P_{p} \in\left[P_{k}, P_{s}\right]$, where $A_{s}=\frac{A_{p}}{A_{k}} \sqrt{\frac{A_{h}}{A_{k}}}$.

The equation (20) was solved by the numerical bisection method [20], then gap $H$ was determined using the formula

$$
H=\sqrt{\frac{A_{k} \Pi\left(P_{p}, P_{k}\right)}{A_{h}\left(P_{k}^{2}-1\right)} .}
$$

In studying the bearing and finding a solution to the problem (11) - (13), it was assumed that the deviation of dynamic functions from their stationary values is insignificant. Moreover, dynamic functions were represented as

$$
D(\tau)=D_{0}+\Delta D(\tau)
$$

where $D_{0}, \Delta D(\tau)$ are the static part and the small dynamic component of the function.

Linearised and Laplace-transformed equations (2) have the form

$$
\left\{\begin{array}{l}
\overline{\Delta Q_{p}}-\overline{\Delta Q_{v}}-\overline{\Delta Q_{k}}=0 \\
\overline{\Delta Q_{k}}-\overline{\Delta Q_{h}}=0 \\
\overline{\Delta W}-\overline{\Delta F_{i n}}=\overline{\Delta F}
\end{array}\right.
$$

where, in the general case, the Laplace transform of the deviation of the dynamic function $\Delta D(\tau), s$ is the variable of the Laplace transform.

The Laplace transforms of the mass flow deviations included in (21) can be written as

$$
\begin{gathered}
\overline{\Delta Q_{p}}=A_{p p} \overline{\Delta P_{p}}, \\
\overline{\Delta Q_{k}}=A_{k k} \overline{\Delta P}_{k}+A_{k p} \overline{\Delta P}_{p}+A_{k h} \overline{\Delta H}, \\
\overline{\Delta Q_{v}}=A_{v} s \overline{\Delta P_{p}}, \\
\overline{\Delta Q_{h}}=3 Q_{h 0} \overline{\Delta H}+2\left[R \frac{\partial}{\partial R}\left(P_{0} \frac{\partial \overline{\Delta P}}{\partial R}\right)\right]_{R=R_{c}+0} \\
-2\left[R \frac{\partial}{\partial R}\left(P_{0} \frac{\partial \overline{\Delta P}}{\partial R}\right)\right]_{R=R_{c}-0},
\end{gathered}
$$

where

$$
\begin{aligned}
& \frac{\partial \Pi\left(P_{1}, P_{2}\right)}{\partial P_{1}}= \begin{cases}\frac{P_{2}}{2 \Pi\left(P_{1}, P_{2}\right)}, & P_{2} / P_{1}>0.5, \\
0.5, & P_{2} / P_{1} \leq 0.5,\end{cases} \\
& \frac{\partial \Pi\left(P_{1}, P_{2}\right)}{\partial P_{2}}= \begin{cases}\frac{0.5 P_{1}-P_{2}}{\Pi\left(P_{1}, P_{2}\right)}, & P_{2} / P_{1}>0.5, \\
0, & P_{2} / P_{1} \leq 0.5,\end{cases} \\
& A_{k k}=A_{k} \frac{\partial \Pi\left(P_{p 0}, P_{k 0}\right)}{\partial P_{k 0}}, \quad A_{k p}=A_{k} \frac{\partial \Pi\left(P_{p 0}, P_{k 0}\right)}{\partial P_{p 0}}, \\
& A_{k h}=A_{k} \Pi\left(P_{p 0}, P_{k 0}\right), \quad A_{p p}=A_{P} \frac{\partial \Pi\left(P_{s}, P_{p 0}\right)}{\partial P_{p 0}} .
\end{aligned}
$$

For bearing capacity and inertia, the corresponding Laplace transforms can be written as

$$
\begin{aligned}
& \overline{\Delta W}=2 \pi \int_{0}^{1} R \overline{\Delta P} d R, \\
& \overline{\Delta F_{\text {in }}}=M s^{2} \overline{\Delta H} .
\end{aligned}
$$

The functions $\overline{\Delta W}, \overline{\Delta Q_{h}}$ are determined by the distributed pressure transform $\overline{\Delta P}$, which, as follows from (6) $-(8)$, is a solution to the boundary value problem

$$
\left\{\begin{array}{l}
\frac{\partial}{\partial R}\left[R \frac{\partial(P \overline{\Delta P})}{\partial R}\right]=\frac{\sigma \mathrm{s}}{H^{3}} R(H \overline{\Delta P}+P \overline{\Delta H}), \\
\frac{\partial \overline{\Delta P}(0, s)}{\partial R}=0, \quad \overline{\Delta P}\left(R_{c}, s\right)=\overline{\Delta P}_{k}, \quad \overline{\Delta P}(1, s)=0,
\end{array}\right.
$$


where $H, P$ is the static gap and the function of the static pressure distribution.

A finite-difference grid method was applied to problem (28), which allows one to obtain its solution with high accuracy. The variable $s$ in this case acts as a complex parameter.

For this, segments $\left[0, R_{c}\right]$ and $\left[R_{c}, 1\right]$ were divided into $n$ equal parts and, having performed the transition from the differential form to the algebraic form in (28), we obtained a system of algebraic equations for each segment

$$
\begin{aligned}
& R_{i} \frac{P_{i+1} \overline{\Delta P}_{i+1}-2 P_{i} \overline{\Delta P}_{i}+P_{i-1} \overline{\Delta P}_{i-1}}{g^{2}}+ \\
& +\frac{P_{i+1} \overline{\Delta P}_{i+1}-P_{i-1} \overline{\Delta P}_{i-1}}{2 g}= \\
& =\sigma \mathrm{s} R_{i}\left(H \overline{\Delta P}_{i}+P_{i} \overline{\Delta H}\right),
\end{aligned}
$$

where $g$ is the grid step, $i=1,2, \ldots, n$.

The boundary conditions for the first segment are the equations

$$
-\overline{\Delta P}_{2}+4 \overline{\Delta P}_{1}-3 \overline{\Delta P}_{0}=0, \quad \overline{\Delta P}_{n}=\overline{\Delta P}_{k},
$$

for the second one

$$
\overline{\Delta P}_{0}=\overline{\Delta P}_{k}, \overline{\Delta P}_{n}=0 .
$$

Using the superposition method, the solution to problems on the segments was sought in the form

$$
\overline{\Delta P}(R, s)=U_{k}(R, s) \overline{\Delta P}_{k}+U_{h}(R, s) \overline{\Delta H} .
$$

For both segments, problems (23) - (25) resulted in the general form

$$
\begin{aligned}
& \left(2 R_{i}+g\right) P_{i+1} U_{i+1}+\left(2 R_{i}-g\right) P_{i-1} U_{i-1}- \\
& -R_{i}\left(4 P_{i+1}+\gamma\right) U_{i}-\delta R_{i} P_{i}=0,
\end{aligned}
$$

where $U$ is the desired function, $\gamma=\frac{2 g^{2} \sigma s}{H^{2}}, \delta=\frac{2 \alpha g^{2} \sigma s}{H^{3}}$, $\alpha=0$ corresponds to the function $U_{k}, \alpha=1$ to the function $U_{h}$. [3]

For $R=0$, the boundary condition is the dependence

$$
\frac{-3 U_{0}+4 U_{1}-U_{2}}{2 g}=0
$$

which approximates the first derivative of the function $U(R)$ at the endpoint $R=0$ with an accuracy of the order of $O\left(g^{2}\right)[21]$.

Problem (30), (33) was solved by the sweep method [22], accepting

$$
U_{i-1}=E_{i} U_{i}+G_{i}
$$

Comparing (34) and (33) for $i=1$, we obtained the initial values of the sweep coefficients

$$
E_{1}=-\frac{C_{1}}{D_{1}}, \quad G_{1}=\frac{\delta R_{1} P_{1}}{D_{1}}
$$

where

$$
\begin{aligned}
& D_{1}=-3\left(2 R_{1}+g\right) P_{2}+\left(2 R_{1}-g\right) P_{0}, \\
& C_{1}=4\left(2 R_{1}+g\right) P_{2}-R_{1}\left(4 P_{1}+\gamma\right) .
\end{aligned}
$$

For another endpoint of the segment $R=R_{c}$

$U_{n}=1-\alpha$.

For segment $\left[R_{c}, 1\right]$, the corresponding boundary conditions have the form

$$
E_{1}=0, G_{1}=1-\alpha, U_{n}=0 .
$$

Substituting (35) into (33), we found recurrence formulas for the sweep

$$
E_{i+1}=\frac{\left(2 R_{i}+g\right) P_{i+1}}{T_{i}}, G_{i+1}=\frac{\left(2 R_{i}-g\right) P_{i-1} G_{i}-\delta R_{i} P_{i}}{T_{i}},
$$

where $T_{i}=R_{i}\left(4 P_{i} R_{i}+\gamma\right)-\left(2 R_{i}-g\right) P_{i-1} E_{i}$.

Taking into account superposition (32), the solution of the system of equations (30), (31), (33) is reduced to general procedures

$$
\operatorname{Prb}\left(\alpha, \beta, s, P, A_{w} A_{q}\right) \text {. }
$$

Here, $\alpha, \beta, s, P$ are the input quantities, $A_{w} A_{q}$ are the desired coefficients for the functions or for the transforms of the bearing capacity and air flow rate at the entrance to the carrier gap of the bearing, where $\beta=0$ corresponds to the segment $\left[0, R_{c}\right], \beta=1$ to segment $\left[R_{c}, 1\right]$.

When calculating the criteria of the bearing dynamics for each value of the complex variable $s$, numerically solving the problems $\operatorname{Prb}\left(0,0, s, P, A_{w 00} A_{q 00}\right)$, $\operatorname{Prb}\left(1,0, s, P, A_{w 10} A_{q 10}\right), \operatorname{Prb}\left(1,0, s, P, A_{w 10} A_{q 10}\right)$, $\operatorname{Prb}\left(1,1, s, P, A_{w 11} A_{q 11}\right)$, we can get the output parameters and find the quantities

$$
\begin{aligned}
& A_{w k}=A_{w 00}+A_{w 10}, A_{w h}=A_{w 10}+A_{w 11}, \\
& A_{q k}=A_{q 10}-A_{q 00}, A_{q h}=A_{q 11}-A_{q 10},
\end{aligned}
$$

which are coefficients for the transforms

$$
\begin{aligned}
& \overline{\Delta W}=A_{w k} \overline{\Delta P}_{k}+A_{w h} \overline{\Delta H}, \\
& \overline{\Delta Q_{h}}=A_{q k} \overline{\Delta P}_{k}+A_{q h} \overline{\Delta H} .
\end{aligned}
$$

The tasks of the Prb procedure are systems of linear equations of the form

$$
A\left(U_{0}, U_{1}, \ldots, U_{n}\right)^{T}=\left(B_{0}, B_{1}, \ldots, B_{n}\right)^{T},
$$

in which the elements of matrix $A$ and vector $B$ are the values of the polynomials of variable $s$. The numerically obtained elements of the solution vector $U_{i}$ of system (38) will obviously be the values of rational functions of this variable. This is demonstrated in visual form by Cramer's rule [23], which gives a solution to the system (38) in the form of a relation of determinants of matrices whose elements, as mentioned, are the values of polynomials of the variable $s$, and therefore this relation itself will also be the value of a rational function of this variable. This circumstance is the basis and is used below nor the development of an algorithm for determining the coefficients of the transfer function of the bearing, as a dynamic system.

Coefficients $A_{w k}, A_{w h}$ were calculated using the Simpson method of calculating a certain integral [24]. Coefficients $A_{q k}, A_{q h}$ were calculated using terminal finite-difference formulas providing quadratic accuracy $O\left(g^{2}\right)$ for calculating the derivatives of the functions $U(R)$ in expressions (19) at the ends of the integration intervals [25]. 
Using equations (21) - (25), (36), (37), the model of the bearing dynamics can be represented in a matrix form

$$
\left[\begin{array}{ccccccccc}
0 & 0 & 0 & 1 & -1 & 0 & 0 & 0 & 0 \\
-s^{2} & 0 & 0 & 0 & 1 & 0 & 0 & 0 & 0 \\
0 & 0 & 0 & 0 & 0 & 0 & -1 & 1 & -1 \\
0 & 0 & 0 & 0 & 0 & 1 & -1 & 0 & 0 \\
0 & 0 & -A_{p p} & 0 & 0 & 0 & 0 & 1 & 0 \\
-A_{k h} & -A_{k k} & -A_{k p} & 0 & 0 & 0 & 1 & 0 & 0 \\
-A_{q h} & -A_{q k} & 0 & 0 & 0 & 1 & 0 & 0 & 0 \\
-A_{w h} & -A_{w k} & 0 & 1 & 0 & 0 & 0 & 0 & 0 \\
0 & 0 & -A_{p} s & 0 & 0 & 0 & 0 & 0 & 1
\end{array}\right]\left[\begin{array}{l}
\overline{\Delta H}_{\overline{\Delta P}} \\
\overline{\Delta P}_{p} \\
\overline{\Delta P}_{i n} \\
\bar{\Delta}_{h} \\
\overline{\Delta Q}_{h} \\
\overline{\Delta Q}_{k} \\
\overline{\Delta Q}_{v}
\end{array}\right]=\left[\begin{array}{l}
1 \\
0 \\
0 \\
0 \\
0 \\
0 \\
0 \\
0 \\
0
\end{array}\right]
$$

The Laplace analogue of the dynamic compliance of the bearing is the function

$$
K(s)=-\frac{\overline{\Delta H}}{\overline{\Delta F}}=\frac{D_{h}(s)}{D_{m}(s)},
$$

where according to Cramer's rule [23]

$$
\begin{aligned}
& D_{m}=A_{k p}\left(A_{k h} A_{w k}+A_{k k} A_{h s}\right)+A_{3}\left(A_{1} A_{w k}+A_{2} A_{h s}\right), \\
& D_{h}=A_{k k} A_{k p}+A_{2} A_{3} . \\
& W_{h s}=A_{w h}+s^{2}, A_{1}=A_{k h}+A_{q h}, \\
& A_{2}=A_{k k}-A_{q h}, A_{3}=A_{p p}-A_{k k}-A_{v} s .
\end{aligned}
$$

Static compliance of the bearing in the "design point" mode

$$
K_{0}=K(0)
$$

As mentioned above, in the general case, the matrix components of the system (39) are rational functions of the Laplace variable. Therefore, function $K(s)$ will also be a rational function of this variable and can be represented in the form

$$
K(s)=\frac{b_{0}+b_{1} s+b_{2} s^{2}+\ldots+b_{n-m} s^{n-m}}{1+a_{1} s+a_{2} s^{2}+\ldots+a_{n} s^{n}},
$$

where $m<n, m>0, n>0 ; n, m$ are natural numbers, $a_{i}$, $b_{i}$ are real numbers.

Number $m$ is constant for the transfer function $K(s)$ and is determined by its smallest natural value, for which the infinite limit is

$$
s^{m} K(s) \rightarrow \frac{b_{n-m}}{a_{n}} \neq 0 .
$$

Numerical experiments showed that for a given transfer function $m=2$. This completely corresponds to the difference in the polynomial orders of the transfer functions of compliance of gas-static bearings, the models of which take into account the influence of the heel mass on their dynamics [26-28].

To find the polynomial coefficients, the functions $K(s)$ (42) were represented as

$$
\begin{aligned}
& b_{0}+b_{1} s+b_{2} s^{2}+\ldots+b_{n-2} s^{n-2}- \\
& -s K(s)\left(a_{1} s+a_{2} s+\ldots+a_{n} s^{n-1}\right)=K(s) .
\end{aligned}
$$

Successively assuming that $s_{i}=\exp (2 \pi i j / k)$, we got a system of linear equations

$$
\begin{aligned}
& b_{0}+b_{1} s_{i}+b_{2} s_{i}^{2}+\ldots+b_{n-2} s_{i}^{n-2}- \\
& -s_{i} K\left(s_{i}\right)\left(a_{1}+a_{2} s_{i}+\ldots+a_{n} s_{i}^{n-1}\right)=K\left(s_{i}\right)
\end{aligned}
$$

relatively unknown coefficients, where $i=0,1,2, \ldots, k-$ $1, k=2 n-1, j$ is the imaginary unit [29].

To determine $n$, the value of which depends on the accuracy of $\varepsilon$ calculations, an iterative algorithm is used, the stopping criterion of which is the fulfillment of the condition

$$
\left|\frac{b_{0}-K_{0}}{K_{0}}\right|<\varepsilon .
$$

Having set a sufficiently small $\varepsilon$ and $n=2$, we solved the system of equations (43), then checked condition (44). If it was not fulfilled, then at a new iteration, $\mathrm{n}$ was increased by one and the system (43) was again solved until condition (44) is satisfied.

Calculations showed that at $\varepsilon=10^{-4}$ the order of the characteristic polynomial in most cases is in the range $n$ $=3-6$.

To assess the quality of the dynamics of the bearing, the root criteria were used [30]:

- degree of stability $\eta=\operatorname{Max} \operatorname{Re}\left\{s_{i}\right\}$, where $s_{i}$ are the zeros of the characteristic polynomial of the dynamical system, which is the polynomial of the denominator of the transfer function (42),

- damping of oscillations over a period $\xi=100[1-\operatorname{Exp}(-|2 \pi \beta / \eta|] \%$, where $\beta$ is the imaginary part of the root of the characteristic equation with the largest real part,

- vibrational index $M$, as a function of the amplitudefrequency characteristic (AFC) of the frequency transfer function $K(j \omega)$.

The degree of stability $\eta$ characterises the speed of the system, i.e. the rate of attenuation of its free oscillations.

The criterion "attenuation of oscillations over a period" $\xi$ can be applied to the assessment of the stability margin of the bearing. The smaller $\xi$, the greater the oscillation will have a transient response, and the system - a smaller margin of stability. It is believed that a dynamical system is well damped if $\xi \geq$ $90 \%$ [30].

The oscillation index $M=\left|K\left(j \omega_{r}\right) / K_{0}\right|$, representing the relative magnitude of the maximum amplitudefrequency modulus at the resonance frequency $\omega_{r}$ reduced to static compliance $K_{0}$, characterises the vibrational properties of the bearing. It is known that the larger $M$ and the higher the resonance peak of the frequency response, the higher the tendency of the dynamic system to fluctuations in frequency response and, conversely, the smaller $M$, the greater its stability margin is.

\section{THEORETICAL ANALYSIS, RESULTS AND DISCUSSION}

The dimensionless input parameters were used in the calculations: the shaft mass $M_{p}=1$, the boost pressure $P_{s}$, the radius $R_{c}$, the coefficients $\chi$ and $\varsigma$, the number $\mathrm{n}$ of division of the segments of the finite difference grid, 
as well as the "compression number" $\sigma$ and volume $V_{p}$. The latter two parameters affect only the dynamic characteristics of the bearing.

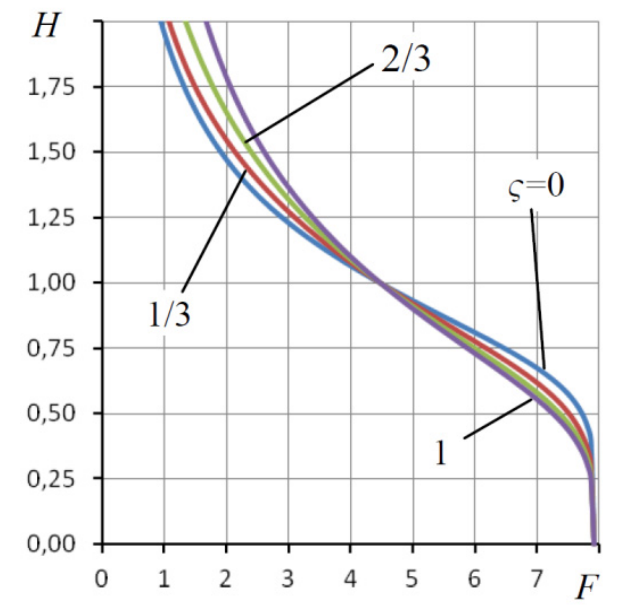

Figure 2. Load curves $H(F)$ for various values of the coefficient at $\boldsymbol{P}_{s}=5, R=0.5,=0.42$

Fig. 2 shows the curves of the static load characteristics of the bearing, which are obtained by solving a system of nonlinear equations (19). The curve $\varsigma=0$ corresponds to the bearing with simple diaphragms, $\varsigma=1$ corresponds to the bearing with annular diaphragms.

As mentioned above, at the "design point" mode $H=$ 1 , the compliance of the latter is 1.5 times higher than the compliance of the former. It follows that, from the point of view of ensuring the minimum conformity of the bearing, values close to $\varsigma=0$ are desirable. Other curves on Fig. 2 correspond to the bearing with combined throttling.

A more detailed idea of the static compliance of the bearing is given by presented by the curves in Fig. 3, which are obtained by calculating the function $K(s)$ at $s$ $=0$ in the "design point" mode of the load curve $H(F)$ of Fig. 2 for which $H=1$.

The curves confirm the conclusions made on the basis of the analysis of load characteristics that less flexibility corresponds to a conventional bearing with simple diaphragms $(\varsigma=0)$, and the greatest compliance is supported by the bearing with annular diaphragms $(\varsigma=1)$.

Other curves relate to the bearing with combined external throttling.

The data presented in the graphs also show that if the dependences $K_{0}(\varsigma)$ are monotonic functions, then the dependences $K_{0}(\chi)$, on the contrary, are unimodal extremal functions. For the given curves, a minimum of compliance occurs at $\chi=0.42$.

Fig. 4 shows the curves of the dependence $\eta(\varsigma)$, which allow to evaluate the influence of the tuning coefficient $\varsigma$ on the dynamics of the bearing with external combined throttling in the vicinity of the "design mode" mode.

The main conclusion is that, given the optimal selection of the values of the dynamic parameters $\sigma$ and $V_{p}$, this dependence is extreme, and the greatest response speed $\eta \approx 0.9$ takes place at $\varsigma=0.1-0.2$, i. e. near the setting factor of the best from the point of view of minimum compliance flexibility $\varsigma=0$. As the curves show, the speed of the bearing with combined throttling is at least 4 times higher than that for the bearing with annular diaphragms $(\varsigma=1)$, which of the single throttle designs is It is the best in terms of dynamic indicators.

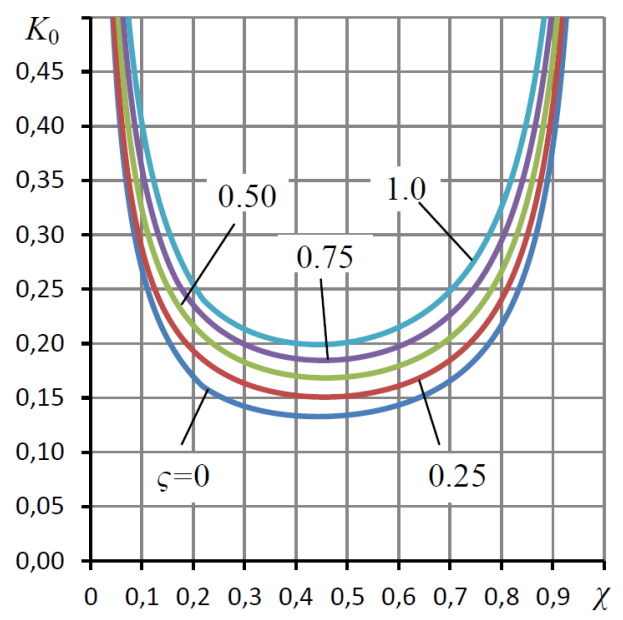

Figure 3. Dependences of the compliance $K_{0}$ of the bearing on the coefficient for different values of the coefficient at $P_{s}=5, R_{c}=0.5$

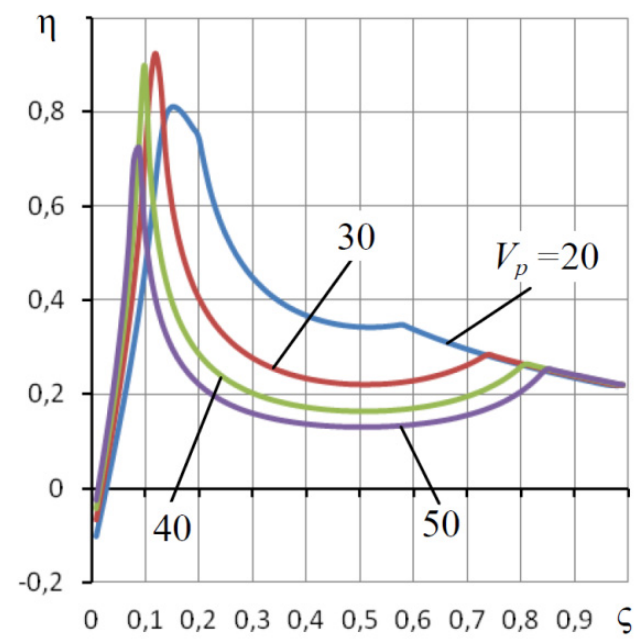

Figure 4. Dependences of the degree of stability on the tuning factor for various values of the volume $V_{p}$ at $P_{s}=5$, $R_{c}=0.5,=0.42,=12$

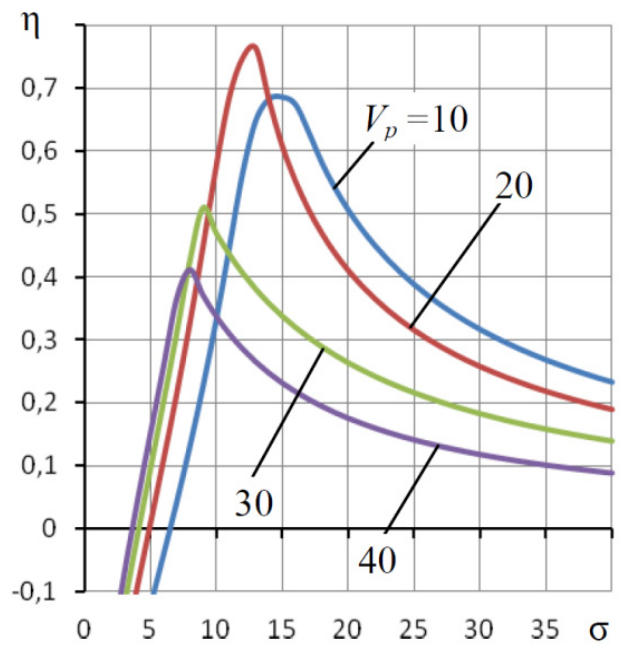

Figure 5. Dependences of the degree of stability on the "compression number" for various values of the volume $V_{p}$ at $P s=5, P_{s}=5, R_{c}=0.5,=0.42,=0.2$ 


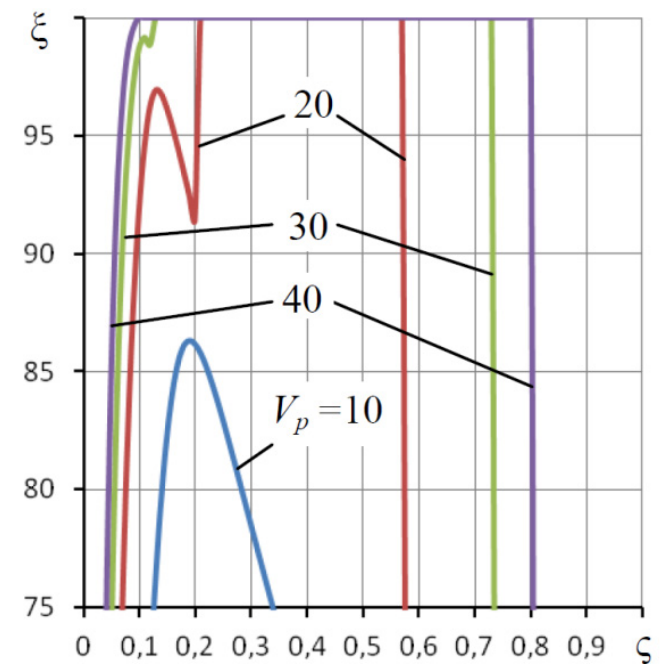

Figure 6. Dependences of the attenuation for the period on the factor for various values of the volume $V_{p}$ at $P_{s}=5$, $R_{c}=0.5,=0.42,=12$

The data presented in Fig. 5 show that the criterion for the speed $\eta$ of the bearing extremely depends on the parameters $V_{p}$ and $\sigma$.

Fig. 6 demonstrates the idea of the vibrational properties of the characteristics, as the curves show the dependences of the oscillation damping index for the period $\xi(\varsigma)$. It can be seen that the extreme modes $\varsigma=0$ and $\varsigma=1$, corresponding to the single throttle bearings, are characterised by unacceptably high oscillation, or, as follows from Fig. 3, the instability that can occur in bearings with simple diaphragms.

In the range $0.1<\varsigma<0.8$ at $V_{p}>20$ and $\sigma>10$, the quality of the dynamics of the bearing corresponds to $\xi=$ $100 \%$, i. e., aperiodic transition characteristics, providing the bearing with a guaranteed margin of stability.

The best values of the analysed parameters $\varsigma, \sigma, V_{p}$ from the point of view of minimum oscillation of the system are given in Fig. 7, which shows the dependences of the oscillation index $M$.

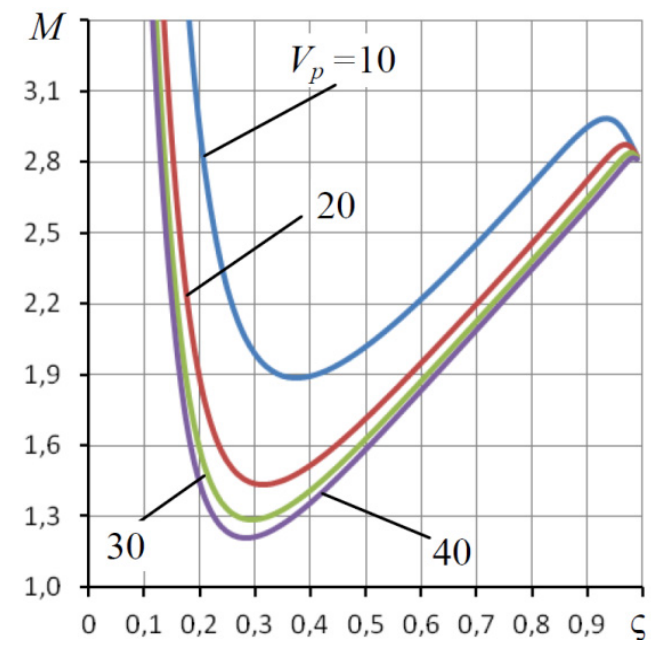

Figure 7. Dependences of the oscillation index $M$ on the factor for various values of the volume $V_{p}$ at $P_{s}=5, R_{c}=$ $0.5,=0.42,=0.2,=12$

As follows from the curves of Fig. 7, the smallest values of this parameter are in the vicinity of the point $\varsigma$ $=0.27$. Acceptable values of $M \leq 2$ are in the range 0.15 $\leq \varsigma \leq 0.65$.
The unsteady movement of the bearing not only at the "design mode", but also in the range of permissible loads on the structure.

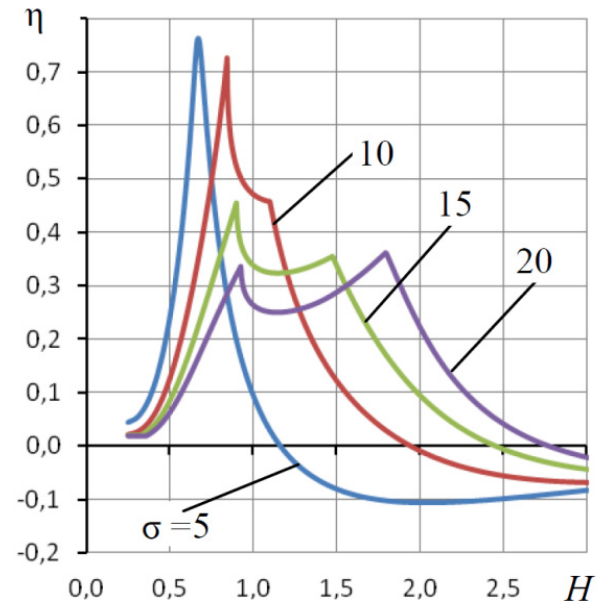

Figure 8. Correspondence of the degree of stability of the load curve $H(F)$ and various values of the "compression number" at $P_{s}=5, R_{c}=0.5,=0.42,=0.2, V_{p}=30$

Fig. 8 shows the curves that prove these conclusions. As follows from the data above, the bearing tends to the boundary of its stability $(\eta=0)$ at the maximum load, which corresponds to the clearance $H=0$. The bearing can lose stability at extremely small loads, when the gap $H$ is 2 to 3 times higher than the calculated operating value $H=1$. It is also seen that by increasing the value of the parameter $\sigma$ this boundary can be substantially shifted to the area of large gaps. It was found that the increase in the volume $V_{p}$ also contributes to the expansion of the range of stable operation of the bearing at extremely small loads.

\section{AN EXAMPLE OF DIMENSIONAL CALCULATION OF THE BEARING}

Let us consider a bearing with an outer radius $r_{b}=4 \cdot 10^{-2}$ $m$. Let us take environmental pressure $p_{a}=0,1 M P a$, air viscosity $\mu=18 \cdot 10^{-6} \mathrm{~Pa} \cdot \mathrm{s}$, heel mass $m_{p}=3 \mathrm{~kg}$. The dimensionless quantities are $P_{s}=5, R_{c}=0.5, \chi=0.42, \varsigma$ $=0.2, \sigma=10, V_{p}=30, \eta=0.75$.

Using the expressions for the dimensionless mass at $M_{p}=1$ and the "compression number" $\sigma$, we found the gap $h_{0}$ of the "design point" mode, the time scale $t_{0}$, the decay time of the transition characteristic $t_{h}$ [30], and the volume of cavity 7

$$
\begin{gathered}
h_{0}=\sqrt[5]{\frac{144 \mu^{2} r_{b}^{6}}{m_{p} p_{a} \sigma^{2}}}=20 \cdot 10^{-6}[\mathrm{~m}], t_{0}=\frac{12 \mu r_{b}^{2}}{h_{0}^{2} p_{a} \sigma}=8.5 \cdot 10^{-3}[\mathrm{~s}], \\
t_{h} \approx \frac{3 t_{0}}{\eta}=3.4 \cdot 10^{-2}[\mathrm{~s}], v_{p}=\pi r_{b}^{2} h_{0} V_{p}=3.1 \cdot 10^{-6}\left[\mathrm{~m}^{3}\right] .
\end{gathered}
$$

In this case, the bearing capacity of the bearing in the "design point" mode is $w=720[N]$, the static compliance $k_{0}=1.9 \cdot 10^{-8}[\mathrm{~m} / \mathrm{N}]$.

\section{CONCLUSION}

A mathematical model of the dynamics of the axial aerostatic bearing has been formulated, numerical methods for determining its static and dynamic characteristics have been developed. 
The application of the approach based on the finitedifference method for solving boundary value problems for the linearised and Laplace-transformed LaplaceReynolds equations to the study of bearing dynamics made it possible to obtain its solution with high accuracy and thereby eliminate the issue of the accuracy of calculating bearing stability criteria that arise when using approximate analytical methods $[2,7,9]$.

Theoretical analysis showed that the optimal choice of parameters of the throttles and the volume of the resonant cavity can significantly improve the dynamic characteristics of the considered bearing. The considered bearing has the highest dynamic characteristics for the volume of the inter-throttle resonant cavity by an order of magnitude and more than the volume of the carrier gas gap, which allows the creation of aerostatic bearings with actively controlled throttling resistances (elastic diaphragms, piezoelectric regulators, etc.), as well as the use of double combined external throttling with inter-throttle resonant chamber for closed axial, as well as radial and radial-axial aerostatic bearings.

The dynamic characteristics of such bearings is many times better, which makes it possible to significantly improve the load characteristics at the same dynamic performance with aerostatic bearings having single external throttling with simple or annular diaphragms due to increased pressure of the injected air.

Thus, an external throttling system is a universal means of improving the quality of the dynamics of gasstatic supports when using devices that help to maintain their low compliance.

\section{ACKNOWLEDGEMENT}

The work was carried out within the framework of the scientific research budget themes «Methods of modeling and optimizing of quality control information systems on the basis of intellectual technologies» at the Department of Standardization, Metrology and Quality Management of the Polytechnic Institute of the Siberian Federal University.

\section{REFERENCES}

[1] Al-Bender, F.: On the modelling of the dynamic characteristics of aerostatic bearing films: from stability analysis to active compensation. Precision Engineering; 33, pp. 117 - 126, 2009.

[2] Oiwa, N., Masaya, M., Hirayama, T., Matsuoka, T., Yabe, H.: Deformation and flying height orbit of glass sheets on aerostatic porous bearing guides. Tribology International, Volume 48, pp. 2 - 7, 2012. https://doi.org/10.1016/j.triboint.2011.08.08.014

[3] Schenk, C., Buschmann, S., Risse, S., Eberhardt, R., Tünnermann, A.: Comparison between flat aerostatic gas bearing pads with orifice and porous feedings at high vacuum conditions. Precision Engineering, Volume 32, Issue 4, pp. 319 - 328, 2008. https://doi.org/10.1016/j.precisioneng.2008.01.00.00

[4] Majumder, M., Majumdar, B.: Nonlinear transient analysis for an externally pressurized porous gas journal bearing. Wear, Volume 132, Issue 1, Pages
139 - 150, 1989. https://doi.org/10.1016/0043-1648 (89)90208-1

[5] Popovic, M. R., Tanovic, L., Ehmann, K. E.: Cutting Forces Prediction: the Experimental Identification of Orthogonal Cutting Coefficients, FME Transactions, Vol. 45, No. 4, pp. 459-467, 2017.

[6] Rusiński, E., Czmochowski, J., Pietrusiak, D.: Selected Problems in Designing and Constructing Surface Mining Machinery, FME Transactions, Vol. 40, No. 4, pp. 153-164, 2012.

[7] Constantinescu, V.: Gas Lubrication. New York: The American Society of Mechanical Engineers, 709 pp, 1968.

[8] Grassam, N., Powell, J.: Gas lubricated bearings. Butterworth \& Co Publishers Ltd, 1964.

[9] Gross, W.: Gas Film Lubrication. Wiley, New York, London. 1962.

[10] Blondeel, E., Snoeys, R., Devrieze, L.: Dynamic Stability of Esternally Pressurized Gas Bearings, ASME J. of Lubrication Technology, Vol. 102, 1980.

[11] Ausman, A.: An Improved Analytical Solution for Self Acting. Gas Lubricated Journal Bearings, Transactions Amer. Soc. Mech Engineers, Journal of Basic Engineering Series D, 83, No. 2, pp. 188, 1961.

[12] Plessers, P. Snoeys, R.: Dynamic Stability of Mechanical Structures Containing Externally Pressurized Gas Lubricated Thrust Bearings. J. Tribol 110 (2), pp. 271-278, 2009. doi: 10.1115 / 1.3261598.

[13] Robinson, C., Sterry, F.: The Static Strength of Pressure Fed Gas Journal Bearings, Jet Bearings, A.E.R.E. report R/R 2642, 1958.

[14] Wei, M., Jiwen C., Liu Y., Tan J.: Improving the pneumatic hammer stability of aerostatic thrust bearing with recess using damping orifices. Tribology International, Volume 103, pp. 281 - 288, 2016. https://doi.org/10.1016/j.triboint.2016.06.06.009

[15] Loch, E.: Ptneumatich erregte Schwingungen in statischen Laslagern. Konstruktion. Bd, 15, N 8, 1963.

[16] Cornelius, L.: The Variational Principles of Mechanics (4th ed.). New York: Dover Publications Inc., pp. 92, 1970.

[17] Stepanyants, L., Zablotsky, N. Sipenhov, I.: Method of theoretical investigation of externally pressurized gas lubricated bearings. JOLT, trans. ASME, ser. F, 91, pp. 166 - 170, 1969.

[18] Martins, L. R., Guimarães, G. P., Fragassa, C.: Acoustical Performance of Helmholtz Resonators Used as Vehicular Silencers, FME Transactions, Vol. 46, No. 4, pp. 497-502, 2018.

[19] Pinegin, S., Tabachnikov. Yu., Sipenkov, I.: Static and dynamic characteristics of gas-static bearings. Moscow, Nauka, 265 pp, 1982. (in Russian)

[20] Burden, R., Faires, Douglas, J.: The Bisection Algorithm, Numerical Analysis, PWS Publishers, 1985.

[21] Marchuk, G.: Methods of Computational Mathematics. Moscow, Science, 1977. 
[22] Krylov, V., Babkov, V. Monastyrsky, P.: Computational methods. Moscow, Science, 1976. (in Russian).

[23] Hedman, B.: An Earlier Date for Cramer's Rule. Historia Mathematica. 26 (4), pp. 365 - 368. doi: 10.1006 / hmat.1999.2247, 1999.

[24] Dwight, H.: Tables of Integrals and other Mathematical Data. The Macmillan Company, New York, 1961.

[25] Samarsky, A., Gulin, A.: Numerical methods. Moscow, Science, 1989. (in Russian)

[26] Kodnyanko, V.: Stability of the energy-saving adaptive radial hydrostatic bearing with limitation of output flow of lubricant. Journal of the Siberian Federal University. Technics and techology. Krasnoyarsk, T. 3, No. 3. pp. $76-84,2009$. (in Russian).

[27] Kodnyanko, V., Shatokhin, S.: Study of the dynamics of a gas-static support with double throttling of gas in the discharge line. Machine Science, No. 6, pp. $61-$ 73, 1978. (in Russian).

[28] Shatokhin, S., Kodnyanko, V.: Radial gas-static bearing with active regulation of gas flow by elastic compensators. Machine Science, No. 5, pp. 23 - 34, 1981. (in Russian).

[29] Brown, J., Churchill, R.: Complex variables and applications, New York: McGraw-Hill, pp. 276, 1996.
[30] Besekersky, V., Popov, E.: Theory of automatic control systems, Moscow, Profession, pp. 513, 2003. (in Russian).

\section{ТЕОРИЈСКО ПРОУЧАВАҢЕ КВАЛИТЕТА ДИНАМИКЕ АЕРОСТАТИЧНО АКСИЈАЛНОГ ЛЕЖИШТА СА СПОЉАШЫИМ КОМБИНОВАНИМ ПРИГУШИВАЊЕМ}

\section{В.А. Коднијанко, С.Н. Шатокин}

Разматра се дизајн, математичко моделирање и теоријски аспект квалитета динамике код аеростатично аксијалног лежишта са комбинованим двоструким ваздушним пригушивањем и протоком у шупљини. Методом коначних разлика решаван је проблем граничних вредности за линеаризоване Лапласове и Рејнолдсове једначине, што је омогућило да се добије прецизно решење. Индикатори квалитета динамике лежишта су проучавани у зависности од отпорности на амортизацију и пригушивање, као и запремину шупљине. Утврђено је да присуство шупљине значајно доприноси индикаторима квалитета динамике лежишта. Анализа добијених података је потврдила хипотезу да се одговарајућим избором вредности параметара спољашњег система пригушивања може добити дизајн који у поређењу са познатим аеростатичним лежиштима има много боље динамичке карактеристике. 